OPEN ACCESS

Edited by:

Jean-Claude Baron,

University of Cambridge, UK

Reviewed by:

Michael Thaut,

Colorado State University, USA

Kristen L. Hollands,

University of Salford, UK

*Correspondence:

Rachel L. Wright

r.wright.1@bham.ac.uk,

dr.rachelwright@gmail.com

Specialty section:

This article was submitted to

Stroke,

a section of the journal

Frontiers in Neurology

Received: 06 January 2016 Accepted: 16 May 2016

Published: 01 June 2016

Citation:

Wright RL, Bevins JW, Pratt D, Sackley CM and Wing AM (2016)

Metronome Cueing of Walking

Reduces Gait Variability after a

Cerebellar Stroke.

Front. Neurol. 7:84.

doi: 10.3389/fneur.2016.00084

\section{Metronome Cueing of Walking Reduces Gait Variability after a Cerebellar Stroke}

\author{
Rachel L. Wright ${ }^{1,2 *}$, Joseph W. Bevins ${ }^{3}$, David Pratt ${ }^{4}$ Catherine M. Sackley ${ }^{5}$ and \\ Alan M. Wing ${ }^{2}$
}

${ }^{1}$ School of Sport, Exercise \& Rehabilitation Sciences, University of Birmingham, Birmingham, UK, ${ }^{2}$ School of Psychology, University of Birmingham, Birmingham, UK, ${ }^{3}$ Institute of Sport and Exercise Science, University of Worcester, Worcester, UK, ${ }^{4}$ West Midlands Rehabilitation Centre, Birmingham Community Healthcare Trust, Birmingham, UK, ${ }^{5}$ Faculty of Life Sciences \& Medicine, King's College London, London, UK

Cerebellar stroke typically results in increased variability during walking. Previous research has suggested that auditory cueing reduces excessive variability in conditions such as Parkinson's disease and post-stroke hemiparesis. The aim of this case report was to investigate whether the use of a metronome cue during walking could reduce excessive variability in gait parameters after a cerebellar stroke. An elderly female with a history of cerebellar stroke and recurrent falling undertook three standard gait trials and three gait trials with an auditory metronome. A Vicon system was used to collect 3-D marker trajectory data. The coefficient of variation was calculated for temporal and spatial gait parameters. SDs of the joint angles were calculated and used to give a measure of joint kinematic variability. Step time, stance time, and double support time variability were reduced with metronome cueing. Variability in the sagittal hip, knee, and ankle angles were reduced to normal values when walking to the metronome. In summary, metronome cueing resulted in a decrease in variability for step, stance, and double support times and joint kinematics. Further research is needed to establish whether a metronome may be useful in gait rehabilitation after cerebellar stroke and whether this leads to a decreased risk of falling.

Keywords: gait ataxia, auditory cueing, gait variability, gait kinematics, cerebellar stroke, rhythmic auditory stimulation

\section{INTRODUCTION}

Cerebellar infarction accounts for $\sim 3 \%$ of strokes, resulting in an incidence of $\sim 20,000$ cases per year in the USA (1). Gait instability and gait ataxia are reported in over half of those who experience an infarct in the cerebellum (2). Gait ataxia is associated with increased variability in both step time and step length (3), and although similar range of motion patterns were observed at the hip, knee, and ankle, the variability of these patterns were significantly higher for hip and knee motion compared to controls (4). These increases in variability are likely to be caused by the interaction between the stroke-induced deficits in balance control, limb control and coordination, and the resultant adjustments needed to respond to these deficits (5).

Any increase in the variability of gait parameters is of concern as a small increase in stride time variability is associated with a risk of future falls in community-dwelling older adults (6). Stance and 
swing time variability distinguishes between fallers and non-fallers (7), and greater stance time variability is associated with future mobility disability (8). Greater variability in step length and double support time is linearly associated with increased risk of multiple falls in older adults, with a non-linear association for step time variability (9). Both increased stride time and length variability are also associated with falls in cerebellar ataxia (10). The occurrence of falls can lead to an associated fear of falling, which can result in a reduction in activity and community involvement (11). Additionally, a high fear of falling also appears to place an individual at an increased risk of experiencing future falls (12). Therefore, reducing excessive gait variability resulting from a cerebellar stroke is an important concern for health-care professionals.

Temporal and spatial parameters, although providing useful information, only provide global measures of gait function. They do not provide information about potential changes at the hip, knee, and ankle joints. The variability of these joint kinematics are only infrequently reported; however, increased variability has been previously reported for individuals with multiple sclerosis (13) and Parkinson's disease (14), as well as in gait ataxia (4). Therefore, the inclusion of joint angle variability in an assessment of gait variability will provide further information of gait function than by temporal and spatial parameters alone.

Research has shown that auditory rhythm and music can produce an effect on the motor system. Musical rhythms and auditory cues can facilitate muscle activation through the audiomotor pathways at the reticulospinal level (15), and studies have demonstrated the ability to synchronize lower limb movements to auditory cues $(16,17)$. Tapping studies have identified that a complex circuit involving different cortical areas, cerebellum and basal ganglia, are associated with timing and rhythmic processing (18). The posterior superior temporal gyrus and premotor cortex have been shown to be involved in the entrainment of movement to auditory cues (19). It has been suggested that although cerebellar damage may impair the conscious detection of rhythmic variation, it does not appear to effect motor entrainment to rhythmic stimuli (18). Therefore, the use of rhythmic stimuli for cueing movement may be a useful tool in the rehabilitation of movement deficits following a cerebellar stroke.

The use of an auditory cue for walking, such as a metronome, has been used for a variety of patient groups, such as those with Parkinson's disease (20-22), post-stroke hemiparesis (23-26), and Huntingdon's disease (27). For individuals with Parkinson's disease, the use of a metronome reduced stride time and swing time variability, but only when the metronome was set to $10 \%$ higher than the preferred cadence, with the improvements still present 15 min later (21). For individuals with post-stroke hemiparesis, the use of a metronome set to each participant's preferred cadence reduced paretic step time variability when stepping in place (28).

These studies indicate that the use of a metronome to cue gait can be a useful tool in reducing excessive gait variability; however, no study has investigated the use of a metronome with someone after a cerebellar stroke. Therefore, the aim of this case report was to investigate whether metronome cueing of gait produces an immediate effect on gait variability after a cerebellar stroke.

\section{METHODS}

The participant gave written and informed consent prior to the start of the experimental session. Favorable ethical opinion for the study was granted by the local Research Ethics Committee and was carried in accordance with the principles laid down by the Declaration of Helsinki.

\section{Case Description}

A community-dwelling female participant (aged 81 years, height $1.60 \mathrm{~m}$, mass $62.1 \mathrm{~kg}$, Rivermead Gross Motor Function $=10$, Fugl-Meyer lower limb score $=31$ with slight dysmetria observed, International Cooperative Ataxia Rating Scale for gait and posture disturbances $=11$ ) volunteered for this study. Twelve months prior to testing, she was diagnosed with a left cerebellar infarct involving the left posterior inferior cerebral artery (PICA) by CT scan. She had also been diagnosed with atrial fibrillation, and at the time of testing was medicated with metoprolol, digoxin, and cardioplen.

She described her walking style as "feeling like I am drunk, but I am not" and "I feel like I lurch when I walk." She stated that she found walking tiring. She had been given an appropriate stick to walk with by a physiotherapist, but preferred not to use it. She had a history of recurrent falling since her stroke and described falls as initially occurring forwards, but they resulted with impact on her side. The recurrent falling had resulted in a high fear of falling [Falls Efficacy Scale - International $=49$ (29, 30)], with activities, involving walking, evoking the highest concern responses. This high fear of falling resulted in the participant limiting her activities outside the home to when she was accompanied by her spouse.

\section{Gait Assessment}

Whole-body motion data were collected at $60 \mathrm{~Hz}$ using a 15 -camera Vicon system (Vicon Peak, Oxford Metrics Ltd., UK) set up in a large $(17 \mathrm{~m} \times 12 \mathrm{~m} \times 4.5 \mathrm{~m})$ gait laboratory. The full-body Vicon Plug-in Gait (PiG) marker set was used. Custom written software running on a laptop provided clearly audible metronome pulses. The metronome generated a voltage pulse that was passed to the Vicon system to allow integration with the motion capture data.

The participant familiarized herself with walking in the laboratory and then performed three gait trials at her comfortable pace. Her cadence was averaged from these trials to generate the interbeat interval for the metronome. The participant then had a 5-min familiarization period to the metronome. After the familiarization period, a further three gait trials were performed with metronome cueing. The metronome was commenced prior to the initiation of walking, and the participant started to walk when she was ready. The first three steps and last three steps of each walking trial were discarded to allow for acceleration and deceleration.

\section{Data Analysis}

According to typical practice for gait analysis studies, data were combined from individual walking trials for each condition. This allowed 24 steps of data to be collected for analysis for each condition, meeting the recommendations for gait variability studies (31). The coefficient of variation $(\mathrm{CoV})$ was calculated 
as a measure of gait variability for the temporal and spatial gait parameters for the left and right sides.

Marker position data were filtered using the Woltring crossvalidity quintic spline routine (32) to minimize marker trajectory noise. Sagittal hip, knee, and ankle angles were calculated from the kinematic marker data using the PiG model (Vicon Peak, Oxford Metrics Ltd., UK) and reported in degrees. Joint angles were segmented into discrete gait cycles and normalized to $0-100 \%$ of the gait cycle. Means and SDs of the joint angles were calculated at each percent of the gait cycle. The mean of these SDs were then calculated to give a measure of variability of joint motion $(13,33)$.

\section{RESULTS}

The participant's normal walking speed was $0.68 \mathrm{~m} \mathrm{~s}^{-1}$, reducing slightly to $0.65 \mathrm{~m} \mathrm{~s}^{-1}$ when walking to the metronome. Heel strike occurred $0.04 \pm 0.02 \mathrm{~s}$ ahead of the leading edge of the metronome impulse. The $\mathrm{CoV}$ was reduced from 9.9 to $3.8 \%$ and 10.9 to $3.3 \%$ for left and right step times, respectively (see Table 1), from 7.2 to $4.5 \%$ (left) and from 8.0 to $6.8 \%$ (right) for stance times and from 18.7 to $14.8 \%$ (left) and from 18.8 to $14.2 \%$ (right) for double support times when walking in the metronome-cued condition compared to baseline. The $\mathrm{CoV}$ for left and right step lengths was also slightly reduced when walking to the metronome.

There were reductions in the variability of the sagittal joint motion patterns at the hip, knee, and ankle (see Table 2), with the largest decreases in variability occurring in knee motion (baseline left $\mathrm{SD}=3.8$, right $\mathrm{SD}=4.3$; metronome left $\mathrm{SD}=1.5$, right $\mathrm{SD}=1.5$ ). This was particularly apparent during the stance phase of the gait cycle for hip motion (see Figures 1A,B), and during the swing phase for knee (Figures 1C,D), and ankle motion (Figures 1E,F).

\section{DISCUSSION}

The aim of this study was to investigate whether using an auditory metronome to cue gait could reduce excessive gait variability in a

TABLE 1 | Temporospatial gait parameters with and without the metronome.

\begin{tabular}{|c|c|c|c|c|c|c|c|}
\hline & & \multicolumn{3}{|c|}{$\begin{array}{c}\text { Without } \\
\text { metronome }\end{array}$} & \multicolumn{3}{|c|}{$\begin{array}{c}\text { With } \\
\text { metronome }\end{array}$} \\
\hline & & Mean & SD & CoV & Mean & SD & CoV \\
\hline Walking speed $\left(\mathrm{m} \mathrm{s}^{-1}\right)$ & & 0.68 & - & - & 0.65 & - & - \\
\hline Step length (m) & $\begin{array}{l}\text { Left } \\
\text { Right }\end{array}$ & $\begin{array}{l}0.49 \\
0.47\end{array}$ & $\begin{array}{l}0.04 \\
0.04\end{array}$ & $\begin{array}{l}8.17 \\
9.40\end{array}$ & $\begin{array}{l}0.50 \\
0.49\end{array}$ & $\begin{array}{l}0.03 \\
0.04\end{array}$ & $\begin{array}{l}6.95 \\
7.72\end{array}$ \\
\hline Step time (s) & $\begin{array}{l}\text { Left } \\
\text { Right }\end{array}$ & $\begin{array}{l}0.65 \\
0.66\end{array}$ & $\begin{array}{l}0.06 \\
0.07\end{array}$ & $\begin{array}{c}9.93 \\
10.92\end{array}$ & $\begin{array}{l}0.67 \\
0.67\end{array}$ & $\begin{array}{l}0.03 \\
0.02\end{array}$ & $\begin{array}{l}3.84 \\
3.26\end{array}$ \\
\hline Stance time (s) & $\begin{array}{l}\text { Left } \\
\text { Right }\end{array}$ & $\begin{array}{l}0.90 \\
0.95\end{array}$ & $\begin{array}{l}0.07 \\
0.08\end{array}$ & $\begin{array}{l}7.23 \\
7.94\end{array}$ & $\begin{array}{l}0.89 \\
0.91\end{array}$ & $\begin{array}{l}0.04 \\
0.06\end{array}$ & $\begin{array}{l}4.49 \\
6.78\end{array}$ \\
\hline Swing time (s) & $\begin{array}{l}\text { Left } \\
\text { Right }\end{array}$ & $\begin{array}{l}0.43 \\
0.40\end{array}$ & $\begin{array}{l}0.04 \\
0.02\end{array}$ & $\begin{array}{l}8.36 \\
4.45\end{array}$ & $\begin{array}{l}0.43 \\
0.41\end{array}$ & $\begin{array}{l}0.04 \\
0.04\end{array}$ & $\begin{array}{l}8.28 \\
8.80\end{array}$ \\
\hline $\begin{array}{l}\text { Double support } \\
\text { time (s) }\end{array}$ & $\begin{array}{l}\text { Left } \\
\text { Right }\end{array}$ & $\begin{array}{l}0.24 \\
0.24\end{array}$ & $\begin{array}{l}0.05 \\
0.04\end{array}$ & $\begin{array}{l}18.71 \\
18.81\end{array}$ & $\begin{array}{l}0.24 \\
0.23\end{array}$ & $\begin{array}{l}0.04 \\
0.03\end{array}$ & $\begin{array}{l}14.78 \\
14.18\end{array}$ \\
\hline
\end{tabular}

participant who had experienced a cerebellar stroke. Gait ataxia is reported in over half of those with a cerebellar infarct in the PICA territory (2), and the participant had a history of repeated falls since her stroke. Increased stride time and step time variability are associated with a risk of future falls in older adults $(6,9)$ and are associated with falls history in cerebellar ataxia (10). This participant demonstrated higher step time variability at baseline (left $9.9 \%$; right $10.9 \%)$ than would be considered normal $(5.5 \pm 2.6 \%)$ for a woman of her age (34). Cueing by the metronome resulted in a large decrease in step time variability (left 3.8\%; right $3.3 \%$ with cueing) and reduced these values to within a normal range without any significant changes to step times.

The participant displayed higher step length variability at baseline than the normal values previously reported for her age group (34). Increased variability in step length and double support time is linearly associated with an increased risk of multiple falls in older adults (9). Therefore, the decreases in variability of these parameters when walking to the metronome in this participant may reduce her risk of multiple falls if the decreased variability is maintained in everyday walking. Stance time variability during uncued walking was at a level associated with prevalent mobility disability (35). Stance time variability was also reduced when walking to the metronome, with a decrease in the SD of greater than the $0.01 \mathrm{~s}$ previously reported as a clinically meaningful reduction in variability during walking for older adults (36).

The participant in this study displayed normal elderly joint kinematics during walking (37). However, she has higher joint angle variability across the hip, knee, and ankle than has been previously reported for healthy controls and individuals with multiple sclerosis (13), and at the hip and knee than has previously been reported for older adults (33). When walking was cued by the metronome, the variability was decreased in all joint angle measures. With the exception of the right hip, the joint variability measures are within the range of previously reported healthy controls (13) when cued by the metronome.

The participant's reports of falls impacting on the side are a cause for concern, as falls impacting on the side (and therefore in the region of the greater trochanter) are more likely to result in a hip fracture than a forward or backward fall $(38,39)$. Therefore, reducing fall incidence is of primary concern to reduce the risk

\begin{tabular}{|c|c|c|c|c|c|}
\hline & & \multicolumn{2}{|c|}{$\begin{array}{c}\text { Without } \\
\text { metronome }\end{array}$} & \multicolumn{2}{|c|}{$\begin{array}{c}\text { With } \\
\text { metronome }\end{array}$} \\
\hline & & Left & Right & Left & Right \\
\hline \multirow[t]{3}{*}{ Hip } & Peak flexion & 32.6 & 32.2 & 33.5 & 33.5 \\
\hline & Peak extension & -8.9 & -11.7 & -9.1 & -8.0 \\
\hline & Variability (mean SD) & 4.0 & 3.7 & 2.3 & 2.8 \\
\hline \multirow[t]{3}{*}{ Knee } & Peak flexion in stance & 19.8 & 15.4 & 22.8 & 17.9 \\
\hline & Peak flexion in swing & 53.2 & 54.0 & 55.8 & 56.7 \\
\hline & Variability (mean SD) & 3.8 & 4.3 & 1.5 & 1.5 \\
\hline \multirow[t]{3}{*}{ Ankle } & Peak dorsiflexion & 15.6 & 15.7 & 16.6 & 18.7 \\
\hline & Peak plantarflexion & -5.9 & -7.5 & -6.2 & -6.3 \\
\hline & Variability (mean SD) & 2.7 & 2.6 & 1.2 & 1.2 \\
\hline
\end{tabular}



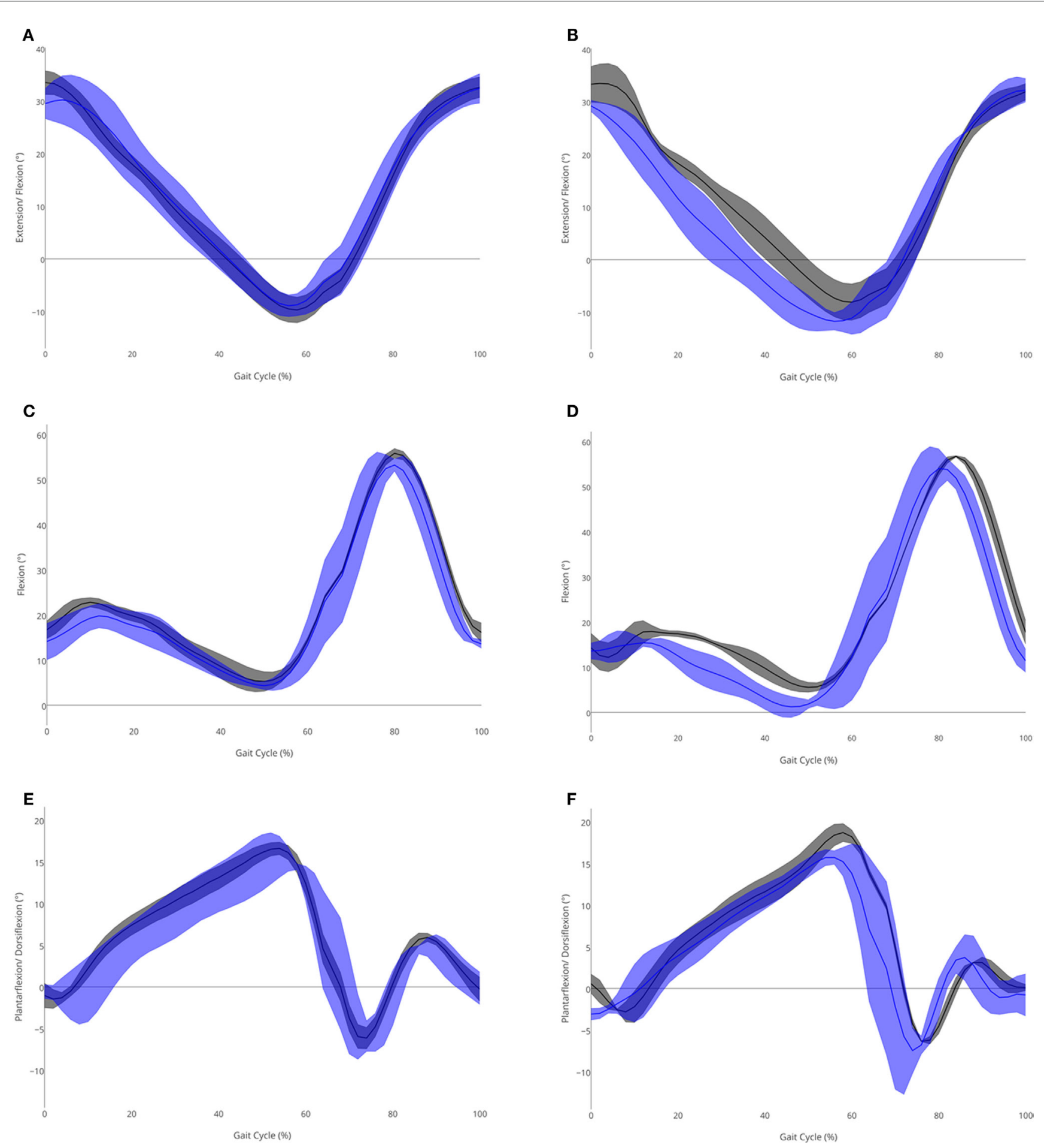

FIGURE 1 | Sagittal joint angles ( ${ }^{\circ}$ ) in the metronome (gray) and no metronome (blue) conditions for (A) left hip, (B) right hip, (C) left knee, (D) right knee, (E) left ankle, and (F) right ankle. Means (solid lines) and SDs (shaded area) shown.

of serious injury. Participant fatigue prevented any investigation of an immediate carry-over effect of the metronome on reducing gait variability, and whether a reduction in gait variability also resulted in reduced fall occurrence in this participant is beyond the scope of this study. However, any potential reduction in fall incidence may also reduce the participant's fear of falling allowing her to be less dependent on company to leave the house. A low fear of falling is thought to have a protective effect against fall 
occurrence (12). Therefore, future research is required on the use of rhythmic cues to reduce excessive gait variability in groups prone to falling.

The motor system is very sensitive to stimulation by the auditory system (15), and studies have demonstrated the ability to time footfalls to auditory cues $(16,17)$. The coupling of footfalls to acoustic pacing has been termed auditory-motor anchoring, and this influences coordinative stability and movement variability at this phase of the gait cycle $(24,40)$. Auditory cueing of gait has been investigated in a variety of different pathologies and has been proposed as one of the most promising approaches to improve gait coordination in post-stroke hemiparesis (41). Therefore, auditory cueing is worthy of investigation in other pathologies affecting gait, such as ataxia after cerebellar stroke.

This case report suggests that the use of a rhythmic auditory cue, such as a metronome, produces an immediate effect on excessive gait variability in a participant with cerebellar stroke.

\section{REFERENCES}

1. Edlow JA, Newman-Toker DE, Savitz SI. Diagnosis and initial management of cerebellar infarction. Lancet Neurol (2008) 7(10):951-64. doi:10.1016/ S1474-4422(08)70216-3

2. Kase CS, Norrving B, Levine SR, Babikian VL, Chodosh EH, Wolf PA, et al. Cerebellar infarction. Clinical and anatomic observations in 66 cases. Stroke (1993) 24(1):76-83. doi:10.1161/01.STR.24.1.76

3. Ebersbach G, Sojer M, Valldeoriola F, Wissel J, Muller J, Tolosa E, et al. Comparative analysis of gait in Parkinson's disease, cerebellar ataxia and subcortical arteriosclerotic encephalopathy. Brain (1999) 122:1349-55. doi:10.1093/brain/122.7.1349

4. Stolze H, Klebe S, Petersen G, Raethjen J, Wenzelburger R, Witt K, et al. Typical features of cerebellar ataxic gait. J Neurol Neurosurg Psychiatry (2002) 73(3):310-2. doi:10.1136/jnnp.73.3.310

5. Ilg W, Timmann D. Gait ataxia - specific cerebellar influences and their rehabilitation. Mov Disord (2013) 28(11):1566-75. doi:10.1002/mds.25558

6. Hausdorff JM, Rios DA, Edelberg HK. Gait variability and fall risk in community-living older adults: a 1-year prospective study. Arch Phys Med Rehabil (2001) 82(8):1050-6. doi:10.1053/apmr.2001.24893

7. Hamacher D, Singh NB, Van Dieen JH, Heller MO, Taylor WR. Kinematic measures for assessing gait stability in elderly individuals: a systematic review. J R Soc Interface (2011) 8(65):1682-98. doi:10.1098/rsif.2011.0416

8. Brach JS, Studenski SA, Perera S, VanSwearingen JA, Newman AB. Gait variability and the risk of incident mobility disability in community-dwelling older adults. J Gerontol A Biol Sci Med Sci (2007) 62(9):983-8. doi:10.1093/ gerona/62.9.983

9. Callisaya ML, Blizzard L, Schmidt MD, Martin KL, McGinley JL, Sanders LM, et al. Gait, gait variability and the risk of multiple incident falls in older people: a population-based study. Age Ageing (2011) 40(4):481-7. doi:10.1093/ageing/ afr055

10. Schniepp R, Wuehr M, Schlick C, Huth S, Pradhan C, Dieterich M, et al. Increased gait variability is associated with the history of falls in patients with cerebellar ataxia. J Neurol (2014) 261(1):213-23. doi:10.1007/s00415-013-7189-3

11. Zijlstra GAR, van Haastregt JCM, van Eijk JTM, van Rossum E, Stalenhoef PA, Kempen GIJM. Prevalence and correlates of fear of falling, and associated avoidance of activity in the general population of community-living older people. Age Ageing (2007) 36:304-9. doi:10.1093/ageing/afm021

12. Delbaere K, Close JC, Brodaty H, Sachdev P, Lord SR. Determinants of disparities between perceived and physiological risk of falling among elderly people: cohort study. BMJ (2010) 341:c4165. doi:10.1136/bmj

13. Crenshaw SJ, Royer TD, Richards JG, Hudson DJ. Gait variability in people with multiple sclerosis. Mult Scler (2006) 12(5):613-9. doi:10.1177/1352458505070609
Future research is warranted to ascertain whether this is replicated in other participants after a cerebellar stroke and to establish whether the benefits can be maintained using a rhythmic cue as a rehabilitation technique such as a rhythmic auditory stimulation stepwise limit cycle entrainment protocol (26).

\section{AUTHOR CONTRIBUTIONS}

Conceived and designed the experiments: RW, DP, CS, and AW. Data collection and analysis: RW and JB. Wrote the manuscript: RW. Critical revision of manuscript: JB, DP, CS, and AW. All the authors read and approved the final manuscript.

\section{FUNDING}

This study was funded by project grant TSA2009/06 from The Stroke Association, UK.

14. Delval A, Salleron J, Bourriez JL, Bleuse S, Moreau C, Krystkowiak P, et al. Kinematic angular parameters in PD: reliability of joint angle curves and comparison with healthy subjects. Gait Posture (2008) 28(3):495-501. doi:10.1016/j.gaitpost.2008.03.003

15. Thaut MH, Kenyon GP, Schauer MI, McIntosh GC. The connection between rhythmicity and brain function. IEEE Eng Med Biol Mag (1999) 18(2):101-8. doi:10.1109/51.752991

16. Chen HY, Wing AM, Pratt D. The synchronisation of lower limb responses with a variable metronome: the effect of biomechanical constraints on timing. Gait Posture (2006) 23(3):307-14. doi:10.1016/j.gaitpost.2005.04.001

17. Wright RL, Spurgeon LC, Elliott MT. Stepping to phase-perturbed metronome cues: multisensory advantage in movement synchrony but not correction. Front Hum Neurosci (2014) 8:724. doi:10.3389/fnhum.2014.00724

18. Molinari M, Leggio MG, De Martin M, Cerasa A, Thaut M. Neurobiology of rhythmic motor entrainment. Ann N Y Acad Sci (2003) 999:313-21. doi: 10.1196/annals.1284.042

19. Chen JL, Penhune VB, Zatorre RJ. The role of auditory and premotor cortex in sensorimotor transformations. Ann N Y Acad Sci (2009) 1169(1):15-34. doi:10.1111/j.1749-6632.2009.04556.x

20. Thaut MH, McIntosh GC, Rice RR, Miller RA, Rathbun J, Brault JM. Rhythmic auditory stimulation in gait training for Parkinson's disease patients. Mov Disord (1996) 11(2):193-200. doi:10.1002/mds.870110213

21. Hausdorff JM, Lowenthal J, Herman T, Gruendlinger L, Peretz C, Giladi N. Rhythmic auditory stimulation modulates gait variability in Parkinson's disease. Eur J Neurosci (2007) 26(8):2369-75. doi:10.1111/j.1460-9568.2007.05810.x

22. McIntosh GC, Brown SH, Rice RR, Thaut MH. Rhythmic auditory-motor facilitation of gait patterns in patients with Parkinson's disease. JNeurol Neurosurg Psychiatry (1997) 62(1):22-6. doi:10.1136/jnnp.62.1.22

23. Prassas S, Thaut M, McIntosh G, Rice R. Effect of auditory rhythmic cuing on gait kinematic parameters of stroke patients. Gait Posture (1997) 6(3):218-23 doi:10.1016/S0966-6362(97)00010-6

24. Roerdink M, Lamoth CJC, Kwakkel G, van Wieringen PCW, Beek PJ. Gait coordination after stroke: benefits of acoustically paced treadmill walking. Phys Ther (2007) 87(8):1009-22. doi:10.2522/ptj.20050394

25. Thaut MH, McIntosh GC, Rice RR. Rhythmic facilitation of gait training in hemiparetic stroke rehabilitation. J Neurol Sci (1997) 151(2):207-12. doi:10.1016/S0022-510X(97)00146-9

26. Thaut MH, Leins AK, Rice RR, Argstatter H, Kenyon GP, McIntosh GC, et al. Rhythmic auditory stimulation improves gait more than NDT/Bobath training in near-ambulatory patients early poststroke: a single-blind, randomized trial. NeurorehabilNeuralRepair(2007)21(5):455-9.doi:10.1177/1545968307300523

27. Delval A, Krystkowiak P, Delliaux M, Blatt JL, Derambure P, Destée A, et al. Effect of external cueing on gait in Huntington's disease. Mov Disord (2008) 23(10):1446-52. doi:10.1002/mds.22125 
28. Wright RL, Masood A, MacCormac ES, Pratt D, Sackley CM, Wing AM. Metronome cued stepping in place after hemiparetic stroke: comparison of a one and two tone beat. ISRN Rehabil (2013) 2013(2013):1-5. doi:10.1155/2013/157410

29. Yardley L, Beyer N, Hauer K, Kempen G, Piot-Ziegler C, Todd C. Development and initial validation of the falls Efficacy Scale-International (FES-I). Age Ageing (2005) 34(6):614-9. doi:10.1093/ageing/afi196

30. Delbaere K, Close JCT, Mikolaizak AS, Sachdev PS, Brodaty H, Lord SR. The falls Efficacy Scale International (FES-I). A comprehensive longitudinal validation study. Age Ageing (2010) 39(2):210-6. doi:10.1093/ageing/afp225

31. Lord S, Howe T, Greenland J, Simpson L, Rochester L. Gait variability in older adults: a structured review of testing protocol and clinimetric properties. Gait Posture (2011) 34(4):443-50. doi:10.1016/j.gaitpost.2011.07.010

32. Woltring HJ. A Fortran package for generalized, cross-validatory spline smoothing and differentiation. Adv Eng Softw Workstations (1986) 8(2):10413. doi:10.1016/0141-1195(86)90098-7

33. Kang HG, Dingwell JB. Separating the effects of age and walking speed on gait variability. Gait Posture (2008) 27(4):572-7. doi:10.1016/j.gaitpost.2007.07.009

34. Hollman JH, Mcdade EM, Petersen RC. Normative spatiotemporal gait parameters in older adults. Gait Posture (2011) 34(1):111-8. doi:10.1016/j. gaitpost.2011.03.024

35. Brach JS, Wert D, VanSwearingen JM, Newman AB, Studenski SA. Use of stance time variability for predicting mobility disability in community-dwelling older persons: a prospective study. J Geriatr Phys Ther (2012) 35(3):112-7. doi:10.1519/JPT.0b013e318243e5f9

36. Brach JS, Perera S, Studenski S, Katz M, Hall C, Verghese J. Meaningful change in measures of gait variability in older adults. Gait Posture (2010) 31(2):175-9. doi:10.1016/j.gaitpost.2009.10.002
37. Bennett D, Humphreys L, O'Brien S, Kelly C, Orr JF, Beverland DE. Gait kinematics of age-stratified hip replacement patients - a large scale, longterm follow-up study. Gait Posture (2008) 28(2):194-200. doi:10.1016/j. gaitpost.2007.11.010

38. Hayes WC, Myers ER, Robinovitch SN, van den Kroonenberg A, Courtney A, McMahon TA. Etiology and prevention of age-related hip fractures. Bone (1996) 18(1 Suppl):77S-86S. doi:10.1016/8756-3282(95)00383-5

39. Greenspan SL, Myers ER, Kiel DP, Parker RA, Hayes WC, Resnick NM. Fall direction, bone mineral density, and function: risk factors for hip fracture in frail nursing home elderly. Am J Med (1998) 104:539-45. doi:10.1016/ S0002-9343(98)00115-6

40. Fink PW, Foo P, Jirsa VK, Kelso JAS. Local and global stabilization of coordination by sensory information. Exp Brain Res (2000) 134(1):9-20. doi:10.1007/s002210000439

41. Hollands KL, Pelton TA, Tyson SF, Hollands MA, van Vliet PM. Interventions for coordination of walking following stroke: systematic review. Gait Posture (2012) 35(3):349-59. doi:10.1016/j.gaitpost.2011.10.355

Conflict of Interest Statement: The authors declare that the research was conducted in the absence of any commercial or financial relationships that could be construed as a potential conflict of interest.

Copyright (C) 2016 Wright, Bevins, Pratt, Sackley and Wing. This is an open-access article distributed under the terms of the Creative Commons Attribution License (CC $B Y)$. The use, distribution or reproduction in other forums is permitted, provided the original author(s) or licensor are credited and that the original publication in this journal is cited, in accordance with accepted academic practice. No use, distribution or reproduction is permitted which does not comply with these terms. 